
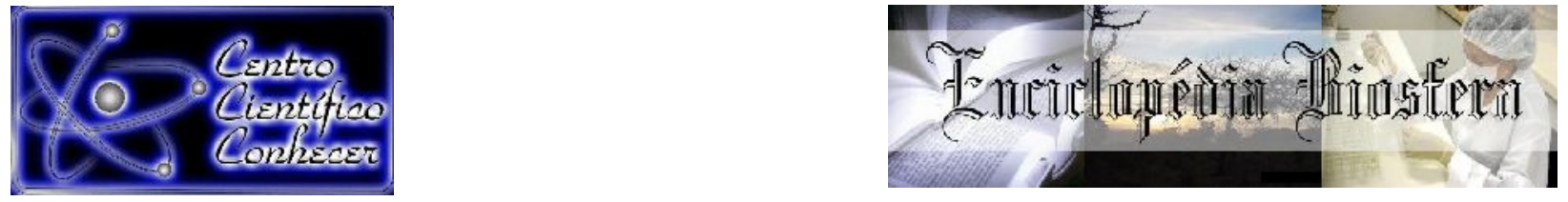

\title{
O USO DA GEOMETRIA PARABOLOIDE PARA MONTAGEM DE UM PROTÓTIPO DE MÓDULO FOTOVOLTAICO
}

\author{
Vítor Abner Borges Dutra ${ }^{1}$, Marcelo José Raiol Souza ${ }^{2}$, Hebe Morganne Campos \\ Ribeiro ${ }^{3}$, Altem Nascimento Pontes ${ }^{4}$
}

${ }^{1}$ Engenheiro Ambiental. Mestrando do Programa de Pós-Graduação em Ciências Ambientais da Universidade do Estado do Pará (abner_dutra_@hotmail.com) Belém, Pará, Brasil.

${ }^{2}$ Doutor em Engenharia de Recursos Naturais. Professor e Pesquisador da Universidade do Estado do Pará.

${ }^{3}$ Doutora em Engenharia Elétrica. Professora e Pesquisadora do Programa de PósGraduação em Ciências Ambientais da Universidade do Estado do Pará.

${ }^{4}$ Doutor em Ciências Físicas. Professor e Pesquisador do Programa de PósGraduação em Ciências Ambientais da Universidade do Estado do Pará.

\section{Recebido em: 22/09/2018 - Aprovado em: 23/11/2018 - Publicado em: 03/12/2018} DOI: 10.18677/EnciBio_2018B115

\section{RESUMO}

Com o fim do petróleo se aproximando, buscam-se alternativas energéticas em escala global, com destaque para a energia solar fotovoltaica, cujo preço está cada vez mais acessível. Este trabalho experimental objetivou gerar energia elétrica com um protótipo de módulo fotovoltaico em geometria paraboloide e um grupo controle (em geometria plana) e compará-los para verificar qual obteve melhor desempenho de potencialidade. Foram arranjadas cinco células flexíveis de silício policristalino sobre a superfície convexa de um prato de antena parabólica e realizaram-se extensivas medições, durante a sazonalidade de Belém do Pará no decorrer do ano (meses de maio, junho, setembro e outubro), tal procedimento também foi realizado com o grupo controle, cujo propósito foi representar o modelo convencional de módulos planos atualmente consolidados no mercado. As medições geraram dados suficientes para equiparar o desempenho de ambos protótipos, onde tanto nos meses de maio e junho quanto nos meses de setembro e outubro o paraboloide proposto obteve melhor desempenho em relação ao grupo controle, com potencialidade superior de 18,82 e 7,84\%, respectivamente. Uma possível aplicação de módulos fotovoltaicos em geometria paraboloide é em postes solares. Com a associação proposta, haveria a vantagem de maior geração de energia, sem custos adicionais com o solar tracking, pois a geometria do módulo viabilizaria a captação em nascente e poente do Sol.

PALAVRAS-CHAVE: antena parabólica, energia solar, reutilização de resíduo.

\section{THE USE OF PARABOLOID GEOMETRY FOR ASSEMBLING A PHOTOVOLTAIC MODULE PROTOTYPE}

\begin{abstract}
With the approach of the end of the oil era, there is an increase in searching for alternative energies on a global scale, especially for the solar photovoltaic, whose
\end{abstract}


price is becoming increasingly accessible. This experimental work aimed to generate electric energy with a solar photovoltaic prototype in a paraboloid geometry and a control group (in flat geometry) and to compare them to verify which one had a better potential performance. It was arranged five flexible polycrystalline silicon solar cells on the convex surface of an antenna dish and were made extensive measures, under a seasonal rainfall of Belém of Pará during the year (months of may, june, september and october). The same procedure was made with the control group whose purpose was to represent the conventional flat model of modules currently consolidated in the market. The measurements generated enough data to compare the performance of both prototypes, where both in months of may and june as in the months of september and october the proposed paraboloid had better performance than the control group with the potentiality of 18.82 and $7.84 \%$, respectively. A possible application of photovoltaic modules in paraboloid geometry is in solar poles. With the proposed association, there would be the advantage of greater energy generation, without additional costs with solar tracking, because the geometry of the module would enable the capture in the east and west of the Sun.

KEYWORDS: parabolic antenna, solar energy, reuse of waste.

\section{INTRODUÇÃO}

O fim do petróleo é um dos principais motivos que levam à busca por melhorias tecnológicas e implementação de energias alternativas em escala global. Modelos matemáticos apontaram que o pico de produção de petróleo bruto foi atingido em 2013, portanto, sua curva produtiva está caminhando de forma decrescente até seu esgotamento nas próximas décadas (MOHR; EVANS, 2008).

As reservas de petróleo bruto em 2015 foram estimadas em 1.493 bilhões de barris de petróleo, um aumento de apenas 0,1\% em relação ao ano de 2014 (OPEC, 2016). Além disso, em 2015 o petróleo bruto sofreu o maior declínio no seu preço desde 1986, em contraste com um vigoroso aumento da geração de energia renovável de consumo primário - cerca de 3\%. Tais mudanças no padrão de produção energética mundial trouxeram um benefício ambiental otimista: os níveis de emissões de carbono voltadas ao consumo de energia aumentaram somente 0,1\% em 2015, o menor crescimento registrado nesse tipo de emissão em 25 anos (BP, 2016).

Apesar desses dados promissores, é evidente que a matriz energética brasileira ainda se encontra muito dependente das usinas hidrelétricas (UHE): de toda oferta interna de energia elétrica por fonte em 2016, cerca de $68,1 \%$ corresponde à hidráulica, seguida de gás natural $(9,1 \%)$, biomassa $(8,2 \%)$, eólica $(5,4 \%)$, carvão e derivados $(4,2 \%)$, nuclear $(2,6 \%)$, derivados do petróleo $(2,4 \%)$ e, por último, solar (0,01\%) (EPE, 2017).

Os baixos níveis dos reservatórios das UHE brasileiras acarretaram no uso imoderado das usinas termelétricas em 2014, refletindo em tarifas maiores de energia e emissões estimadas em 70 bilhões de toneladas de $\mathrm{CO}_{2}$ no mesmo ano; neste âmbito, a energia solar fotovoltaica realizaria um papel complementar às UHE e demais fontes, pois amenizaria o aumento do pico da demanda de energia no decorrer do dia, dada sua isenção de emissões de gases de efeito estufa e fácil instalação local, reduzindo a necessidade de introdução de novas linhas de transmissão (WWF, 2015).

O panorama nacional de energias renováveis demanda mais atenção, dada a alta incidência de radiação solar média no ano, grande disponibilidade de ventos em regiões litorâneas (tanto onshore quanto offshore), ampla disponibilidade de 
biomassa, dentre outros. Nesta conjuntura, o Brasil se comprometeu a cumprir metas acordadas na Contribuição Nacionalmente Determinada (ou ainda Nationally Determined Contributions - NDC), sendo uma das metas a tentativa de expansão do uso de fontes renováveis de 28 a 33\% na matriz total de energia até 2030 (BRASIL, 2016).

Outra forma de estímulo direto ao cenário de energias renováveis no Brasil foi promulgada pela Agência Nacional de Energia Elétrica (ANEEL), através de sua Resolução Normativa no 482/2012 (e suas respectivas alterações pelas Resoluções Normativas no 517/2012 e 687/2015) que instaurou "as condições gerais para o acesso de microgeração e minigeração distribuída aos sistemas de distribuição de energia elétrica [...]" (ANEEL, 2012). Tal iniciativa projetou o cenário nacional para a adesão efetiva de novas fontes de energia alternativas dentro de sua matriz energética.

Ressalta-se que o Brasil possui extensões continentais, cujos estados possuem peculiaridades em relação às suas taxas de insolação e demandas energéticas. Nesta circunstância, o Pará é considerado um dos estados promissores no ramo solar, pois mesmo com elevados índices de precipitação, durante boa parte do ano há condições favoráveis de irradiação disponível para aproveitamento energético fotovoltaico (CAMPOS; ALCÂNTARA, 2016).

\section{Energia solar fotovoltaica}

A energia solar direta fotovoltaica é dada em $\mathrm{kWh} \mathrm{m} \mathrm{m}^{-2} \mathrm{t}^{-1}$, ou seja, a energia transmitida diretamente na superfície do solo durante um determinado tempo (PINHO; GALDINO, 2014). A Figura 1 mostra o mapa solarimétrico do Pará, onde a faixa 4 (5.219-5.274 $\mathrm{kWh} \mathrm{m}^{-2}$ ) abrange a Região Metropolitana de Belém (RMB) (AMORIM, 2016).

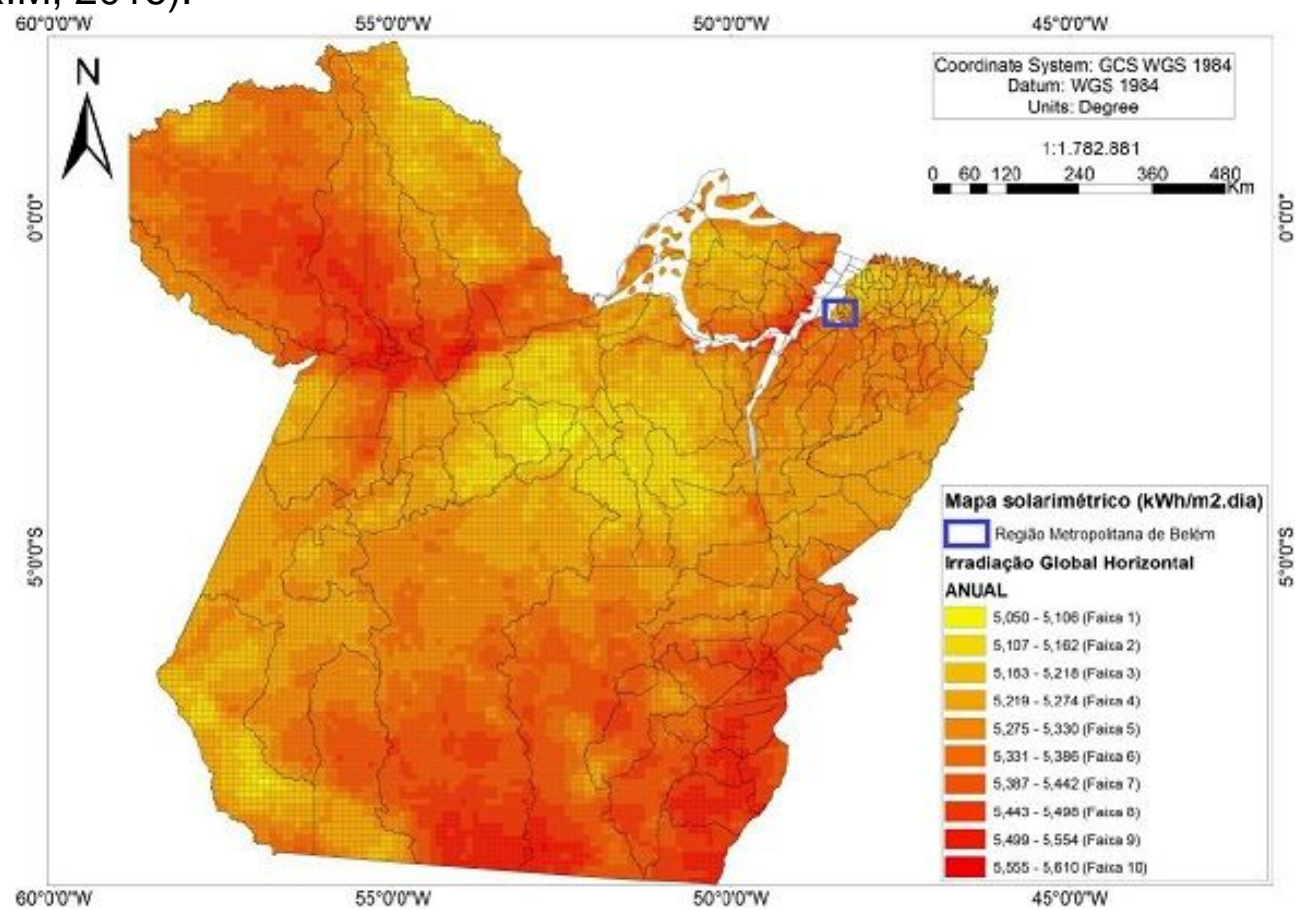

FIGURA 1: Mapa Solarimétrico da Média Anual de Irradiação Solar Global Horizontal no estado do Pará.

Fonte: Adaptado de AMORIM (2016). 
Ressalta-se que todos os valores em qualquer região do estado superam a maioria dos valores encontrados em países da Europa, como Alemanha (900-1.250

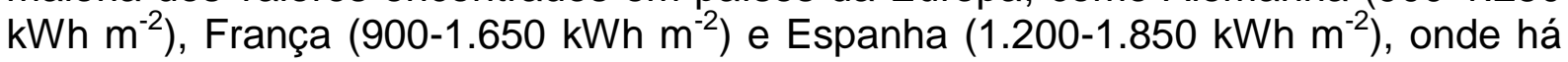
maior utilização da energia solar fotovoltaica em relação ao Brasil (PEREIRA et al., 2006).

A Figura 2 mostra que o aproveitamento solar apresentou o maior decréscimo global no seu custo: cerca de $\$ 0,60 \mathrm{kWh}^{-1}$ desde 2000, o que o colocou em um ponto de inflexão de custo-efetividade de patamares competitivos com o carvão e pequenas centrais hidrelétricas (PCH). Logo, fatores como alta insolação e aumento de demanda por fontes alternativas tornam o Brasil um dos países onde o investimento em energia solar fotovoltaica já se tornou economicamente viável (WEF, 2016).

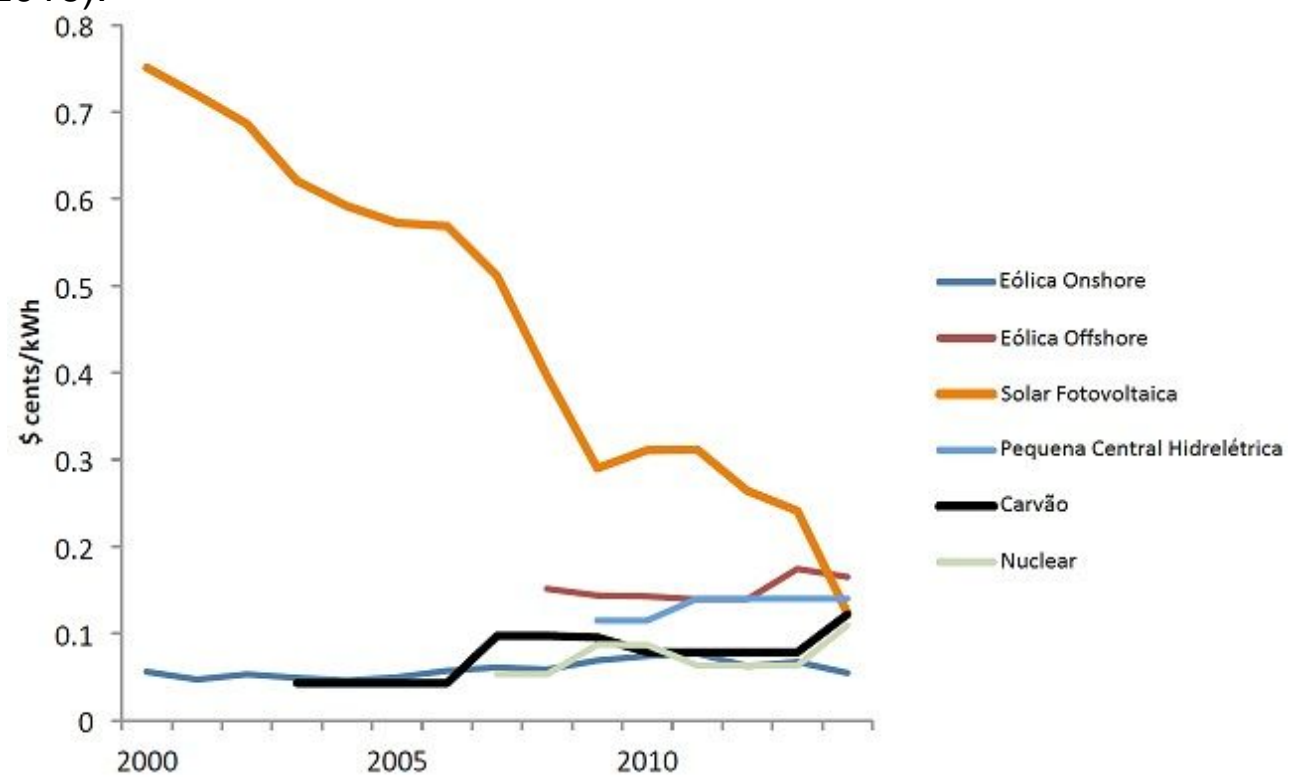

FIGURA 2: Média global do custo de energia por tipo de geração.

Fonte: Adaptado de WEF (2016).

\section{Antenas parabólicas no Brasil}

As antenas parabólicas são um dos principais componentes utilizados na tecnologia Direct to Home (DTH) por empresas de TV por assinatura no Brasil, pois são responsáveis pela captação do sinal eletromagnético na atmosfera. Todo sinal incidente na antena é redirecionado ao foco (onde há um pequeno conversor de sinal denominado Low Noise Block Feedhorn - LNBF), que posteriormente é decodificado pelo receptor para que haja exibição do conteúdo para o cliente (W3SAT, 2017).

A densidade de TV por assinatura a cada 100 domicílios em cada estado é mapeada pela Agência Nacional de Telecomunicações (ANATEL), onde na região norte o estado do Pará detém a maior quantidade de assinantes (304.066) e a terceira maior densidade por 100 domicílios (12,72\%), ficando atrás do Amazonas $(27,48 \%)$ e Acre $(13,14 \%)$ (ANATEL, 2018a).

A tecnologia DTH é dominante no mercado de TV por assinatura no Brasil, e apesar de existirem outras tecnologias, a única que mantém milhões de usuários ativos além da DTH é a TV a cabo (TVC). Desse modo, elaborou-se a Figura $3 \mathrm{com}$ a quantidade de usuários de TV por assinatura que utilizaram ambas tecnologias de 2015 a 2018. 


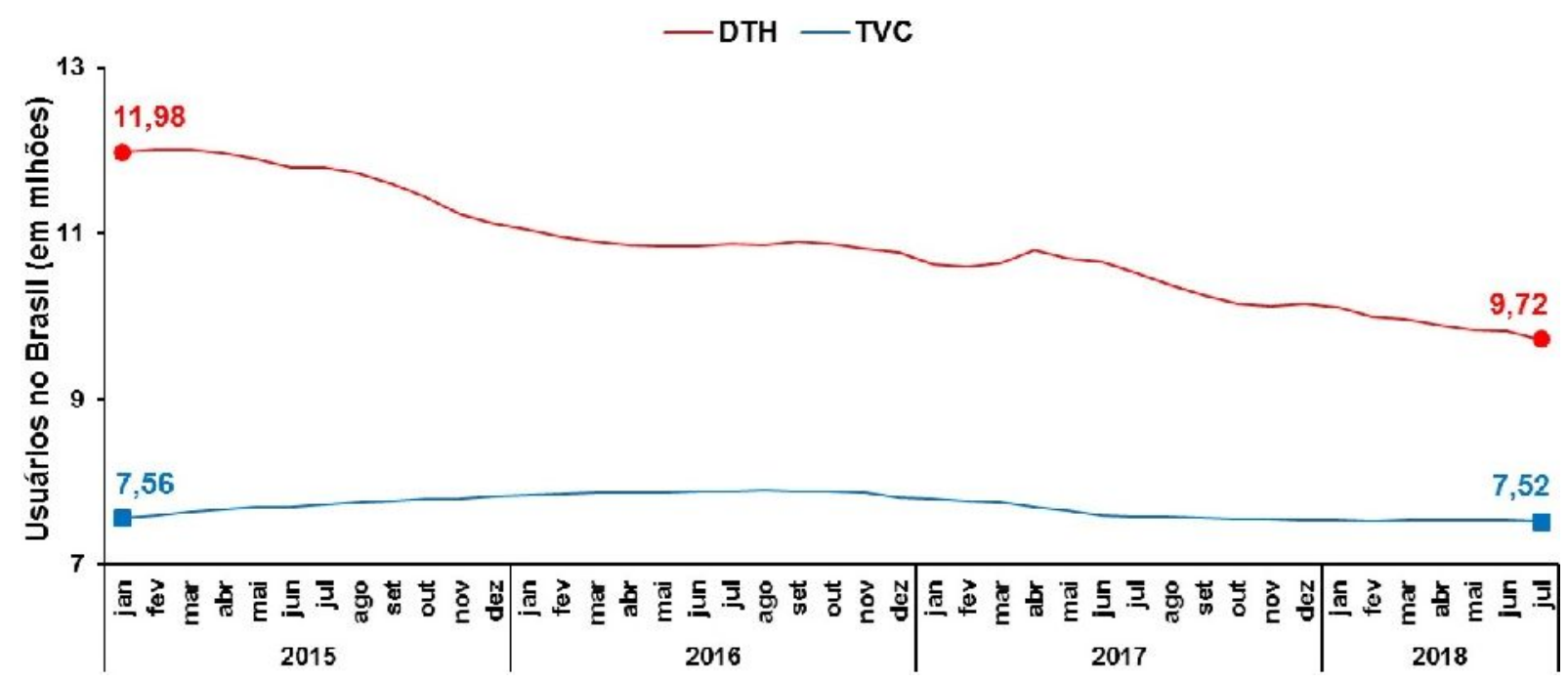

FIGURA 3: Quantidade de assinantes das tecnologias DTH e TVC entre janeiro de 2015 e julho de 2018.

Fonte: Adaptado de ANATEL (2018b).

De janeiro de 2015 a julho de 2018 houve um declínio considerável - em torno de 2,26 milhões de usuários -, somente na tecnologia DTH, ou seja, os serviços foram cancelados ou substituídos por outra tecnologia de TV por assinatura (ANATEL, 2018a). Ressalta-se que a TVC, por não utilizar antenas parabólicas por parte do cliente, foi desconsiderada neste trabalho.

Dito isto, constatou-se que, após ocorrer cancelamento ou mudança do serviço pelo assinante, apenas os receptores de sinal são recolhidos de suas residências, tornando as antenas parabólicas em resíduos sólidos sem destinação final adequada. Salienta-se que a medida de recolhimento por meio de rescisão de contrato para este tipo de equipamento é prescrita pela Resolução no 488, de 3 de dezembro de 2007, da ANATEL, por meio do art. 19, § 5 (ANATEL, 2007).

Nesse contexto, considerando a necessidade de propor um reuso adequado da antena parabólica pós-consumo e de acessibilizar a energia fotovoltaica à população, o objetivo geral do trabalho foi gerar energia elétrica com um protótipo de módulo fotovoltaico em geometria paraboloide em geometria plana (chamada de grupo controle) e compará-los.

\section{Área de estudo}

\section{MATERIAL E MÉTODOS}

O estado do Pará tem população estimada de 8.513.497 habitantes, área total de $1.247 .955 \mathrm{~km}^{2}$, rendimento nominal mensal domiciliar per capita de $R \$ 715,00$ e índice de desenvolvimento humano de 0,646; além disso, possui 144 municípios, sendo Belém sua capital (IBGE, 2018). A Região Metropolitana de Belém (RMB) abrange os municípios de Belém, Ananindeua, Marituba, Benevides e Santa Bárbara, possui área total de $1.827,7 \mathrm{~km}^{2}$, relevo uniforme e pouco acidentado (LIMA; MOYSÉS, 2009).

As coordenadas do ponto escolhido para medições elétricas do protótipo foram -1.423688, -48.474255 (Latitude e Longitude) e estão representadas na Figura 4. A elaboração do mapa foi realizada por meio do freeware QGIS 2.18.8. 


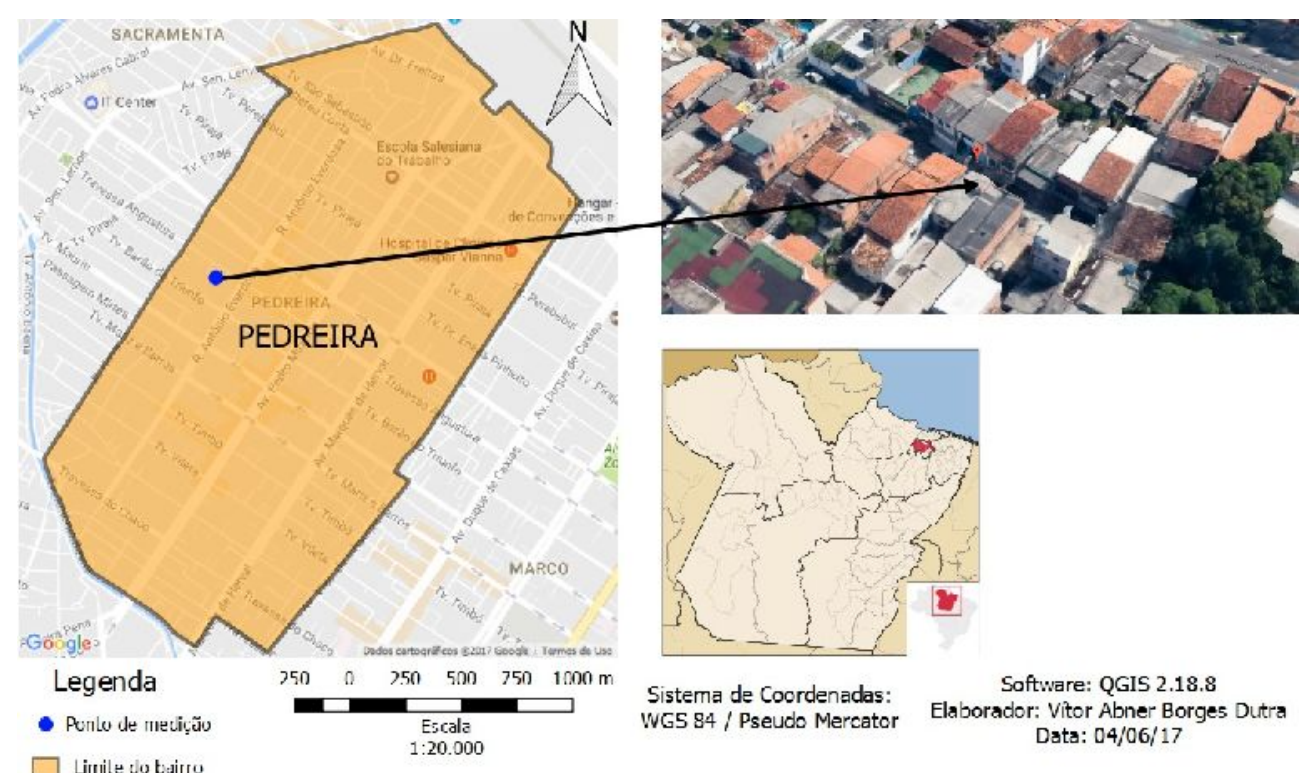

FIGURA 4: Localização do ponto de medição do protótipo.

Fonte: Adaptado de Google Maps (2017).

Optou-se pelo bairro da Pedreira como local das medições, incluso na Zona de Ambiente Urbano 6 (ZAU 6), setor II (BELÉM, 2008), dada a baixa taxa de verticalização comparada aos demais bairros da mesma ZAU, como Umarizal, Batista Campos e Nazaré. Havia pouca presença de prédios residenciais e comerciais nas proximidades, ou seja, existiam poucas áreas sombreadas no entorno.

\section{Característica da pesquisa}

A natureza da pesquisa foi aplicada, pois utilizou tecnologias existentes junto do conhecimento gerado pela pesquisa básica; o objetivo foi exploratório, com levantamento de bibliografia específica da área; e teor foi explicativo, em razão da necessidade de identificar a influência na ocorrência dos fenômenos, a exemplo da chuva e tempo nublado. O procedimento foi considerado experimental, caracterizado pela definição de um objeto de estudo - protótipo de módulo fotovoltaico -, junto da seleção de variáveis (neste caso, elétricas: tensão, corrente e potência) que influenciaram no desempenho do objeto em questão (PRODANOV; FREITAS, 2013).

Foram definidas formas controladoras e observacionais das variáveis, deste modo, foram obtidos dados aproximados de situações reais de causa e efeito. A abordagem do problema ocorreu de forma quali-quantitativa, pois houve geração de dados numéricos, que foram trabalhados em uma conjuntura econômica e ambiental no sentido de reutilizar um resíduo cada vez crescente nas residências, mas ainda sem destinação final adequada.

\section{Características físicas da antena parabólica e definição do arranjo das células fotovoltaicas}

O prato da antena possui formato denominado paraboloide elíptico de revolução, o que proporciona melhor captação na área côncava para posterior decodificação do sinal eletromagnético. Todavia, na confecção do protótipo proposto neste estudo, foi utilizado o lado convexo do prato, para que ocorresse maior captação solar tanto no nascente quanto poente do Sol. O esquema é visível na Figura 5. 

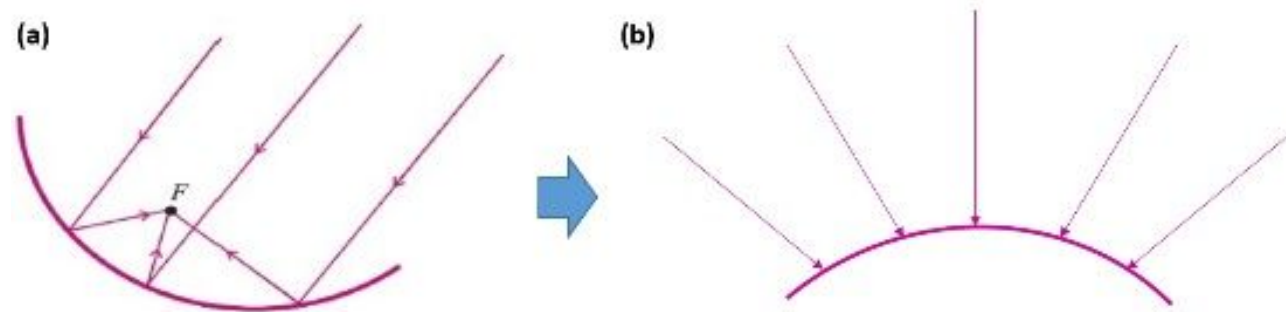

FIGURA 5: (a) uso convencional da superfície côncava da antena parabólica e (b) utilização da geometria paraboloide da parte convexa da antena para aproveitamento energético solar.

Fonte: Adaptado de WAGNER (1997).

Em vista dos atributos descritos anteriormente, desmontou-se uma antena parabólica em desuso e isolou-se apenas seu prato. Os demais componentes braço suporte com LNBF, mastro e base - foram removidos e encaminhados para reciclagem. A Figura 6 ilustra os componentes constituintes da antena parabólica.

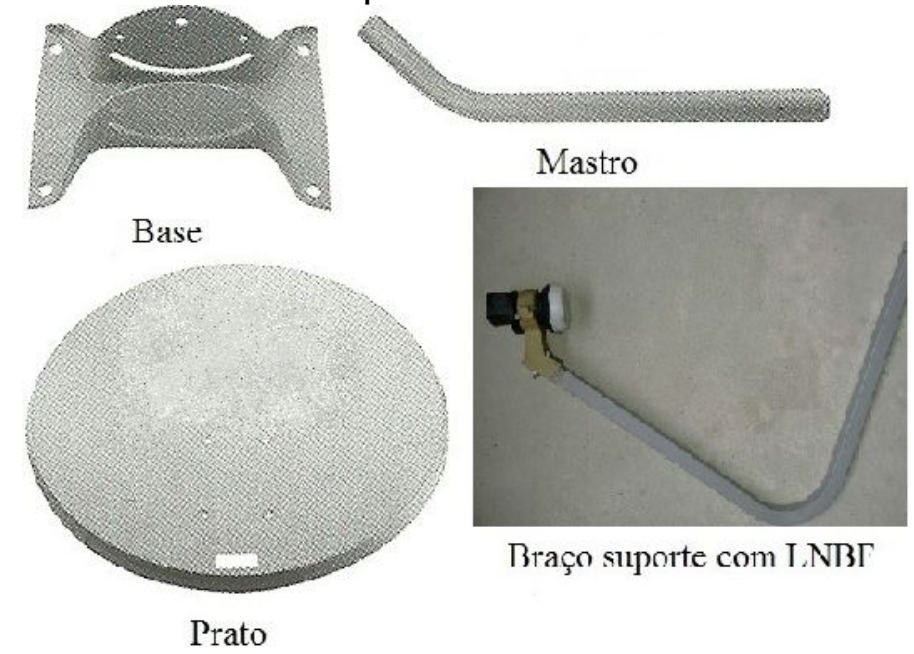

FIGURA 6: Principais componentes da antena parabólica.

Fonte: Adaptado de SERVYCOMS (2013).

Após a separação dos materiais, mediram-se os diâmetros maior (D) e menor (d) do prato, que foram 67 e $62 \mathrm{~cm}$, respectivamente. A mensuração de $\mathrm{D}$ e d foi útil para calcular a área do paraboloide elíptico de revolução $\left(A_{e}\right)$, disponível na Equação 1.

$$
A_{e}=\pi a b=\frac{\pi D d}{4} \cong 3263 \mathrm{~cm}^{2} \therefore A_{e}=0,33 \mathrm{~m}^{2}
$$

O cálculo de $A_{e}$ foi necessário para estabelecer a distribuição adequada das células fotovoltaicas flexíveis na superfície convexa do prato. Foram adquiridas 5 células (com dimensão de cada $12 \times 35 \mathrm{~cm}^{2}$ ), e para encontrar seu melhor arranjo de cobertura $\left(A_{c}\right)$ na superfície do prato, confeccionaram-se réplicas de mesma dimensão com papelão. $\mathrm{O}$ cálculo de $\mathrm{A}_{\mathrm{c}}$ está de acordo com a Equação 2.

$$
A_{c}=(5 \times 12 \times 35) \mathrm{cm}^{2}=2100 \mathrm{~cm}^{2}=0,21 \mathrm{~cm}^{2} \therefore A_{c}=\left(A_{e}\right) 64,38 \%
$$

Como $A_{c}$ foi $64,38 \%$ de $A_{e}$, evidenciou-se que há possibilidade de melhores aproveitamentos tanto de espaço quanto de rendimento para o mesmo tipo de antena, caso sejam confeccionados outros protótipos com células de diferentes dimensões. 


\section{Eficiência de conversão das células}

Utilizou-se o multímetro modelo DT 830-B da marca MTX para verificar o funcionamento das células através das unidades elétricas de corrente e tensão. Todas apresentaram valores satisfatórios próximos aos informados pelo fornecedor: corrente máxima por volta de $2 \mathrm{~A}$ (ampères) e tensão de corrente contínua em torno de $1,8 \mathrm{~V}$ (Volts).

A eficiência das células fotovoltaicas foi calculada a partir da Equação 3 (PINHO; GALDINO, 2014):

$$
\eta=\frac{P_{M P}}{A \times G} \times 100 \%=\frac{4 W}{0,042 m^{2} \times \frac{1000 W}{m^{2}}} \times 100 \therefore \eta \cong 9,5 \%
$$

Onde:

$\eta=$ eficiêncta de conversão

$P_{M P}=$ potência máxima $=4 \mathrm{~W}$ (dados do fornecedor)

$A \equiv$ área coletora da célula $=420 \mathrm{~cm}^{2} \equiv 0,042 \mathrm{~m}^{2}$

$G=1000 \mathrm{~W} \mathrm{~m}^{-2}$ (radiação incidente em testes de condição padrão)

Ressalta-se que essa eficiência de conversão fotovoltaica é duas vezes menor que o máximo atingível $(21,9 \%)$ para esse tipo de célula de silício policristalino (NREL, 2016). Além disso, o $\eta$ das células utilizadas neste trabalho é cerca de cinco vezes menor que o máximo de conversão atingida pelo grupo de pesquisa franco-alemão Fraunhofer, de 46\% (DIMROTH et al., 2016; FRAUNHOFER, 2014). A partir desses dados, seguiu-se para a montagem do protótipo de módulo fotovoltaico e do grupo controle.

\section{Montagem dos módulos solares}

$A_{c}$ foi definida no item (a) da Figura 7. Em seguida, aplicou-se uma fina camada $(5 \mathrm{~mm})$ de emborrachado de EVA $\left(40 \times 60 \mathrm{~cm}^{2}\right.$ - com recortes) da marca Kreateva sobre $A_{c}$. A fixação do EVA foi realizada utilizando cola de contato da marca Brascola e a área emborrachada é visível no item (b) da Figura 7.

Ressalta-se que a etapa de emborrachamento foi importante para que não ocorresse contato direto das células com a superfície do prato, pois haveria interferência térmica e elétrica, visto que a antena possui material metálico na sua composição. O protótipo finalizado foi disposto no item (c) da Figura 7.

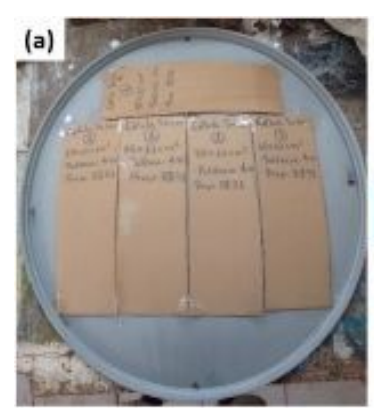

(a) - definição do arranjo espacial ótimo.

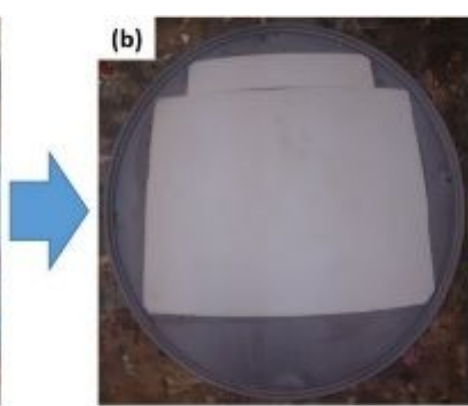

(b) - colagem de emborrachado EVA para recebimento das células.

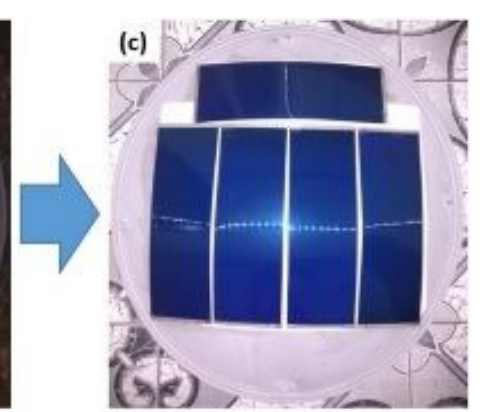

(c) - fixação das células na superfície emborrachada.

FIGURA 7: Fluxograma das etapas de montagem do protótipo em geometria paraboloide.

Fonte: Autores. 
A associação das células foi em série, através da junção dos contatos metálicos do polo positivo de uma com o negativo da outra, como ilustrado pela Figura 8. A fixação dos contatos metálicos com fita adesiva foi o modo mais simples de associar as células, além de facilitar a manutenção do protótipo. A disposição horizontal de uma das células demandou o uso de fiação de cobre para estabelecer sua conexão com as demais.

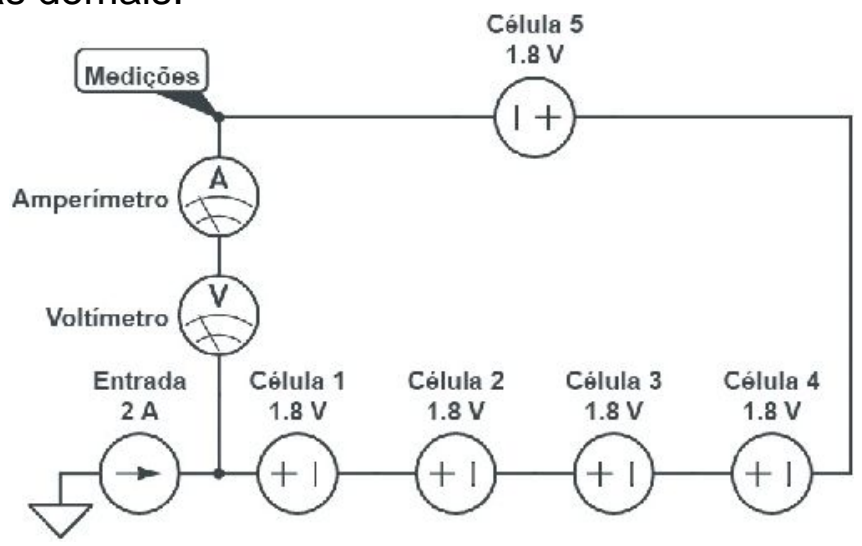

FIGURA 8: Circuito simplificado da associação das células solares.

Fonte: Autores.

Estabeleceu-se um grupo controle para comparar os ganhos do módulo em geometria paraboloide em relação ao modelo convencional plano. Ele foi confeccionado com condições análogas ao módulo proposto neste estudo: mesma quantidade, distribuição e associação elétrica das células sobre $A_{c}$, excetuando-se apenas a geometria, que neste caso foi plana, sobre superfície em compensado.

As medições foram fixadas durante 12 horas por dia, das 6 às $18 \mathrm{~h}$, com uma hora de intervalo entre cada uma. Os dias de mensuração foram fixados aos domingos de maio, junho, setembro e outubro de 2017, para possibilitar a comparação de potencialidade de ambos módulos nos meses com diferentes níveis de precipitação no decorrer de um ano, ou seja, um ciclo sazonal.

\section{RESULTADOS E DISCUSSÃO}

O protótipo proposto (em geometria paraboloide), o grupo controle (em geometria plana), o multímetro e a planilha de anotações das variáveis elétricas se encontram na Figura 9.
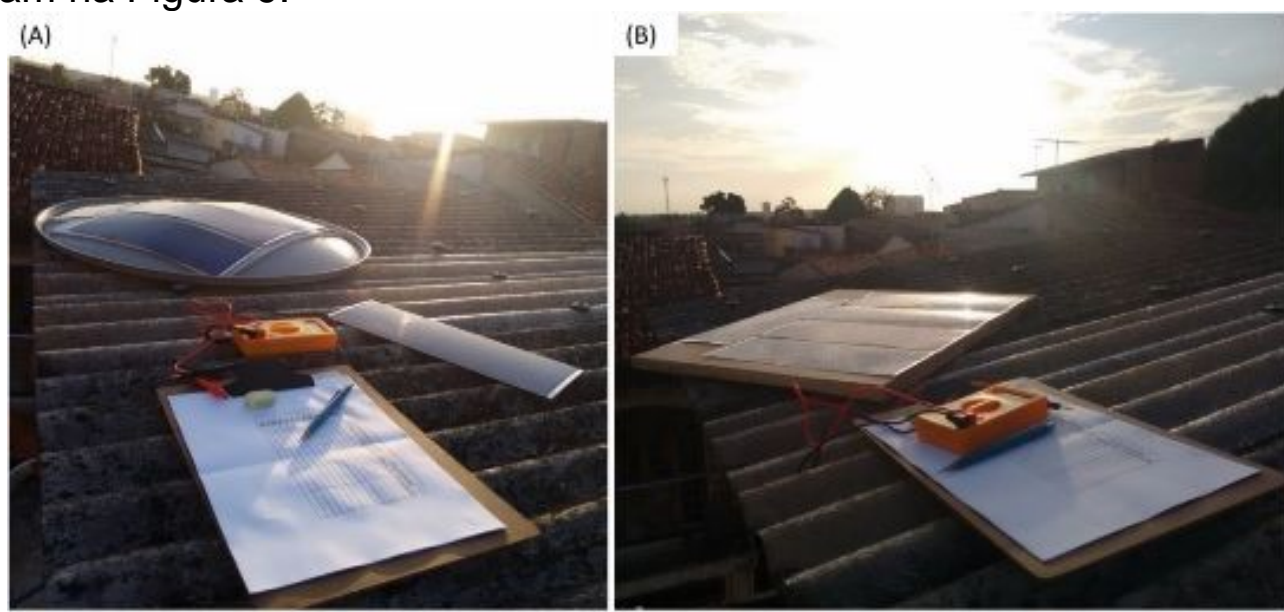

FIGURA 9: Componentes necessários para a realização do estudo, sendo Fonte: Autores.

(A) paraboloide e (B) grupo controle. 
Após as medições, as variáveis registradas na planilha de anotações foram transferidas para planilha eletrônica, onde foi possível estebelecer o cálculo de média dos valores mensurados pelo número de dias coletados para cada módulo. Ressalta-se que os horários em tempo de chuva foram excluídos, pois os componentes elétricos poderiam ser danificados se expostos à água.

Salienta-se que o efeito hotspot (perda de corrente e potência total gerada pelos sistemas através do sombreamento parcial de uma ou mais células) foi insignificante em ambos módulos, dada a baixa potencialidade gerada e o pequeno número de células fotovoltaicas utilizadas nos mesmos. Além disso, desconsideraram-se as perdas tanto de potencialidade dos módulos por resistividade intrínseca do contato metálico frontal das células quanto de rendimento devido a da resistência-série da associação das mesmas.

Ressalta-se que houve aproveitamento satisfatório do albedo - parte da radiação solar que chega à superfície da Terra e é refletida pelo ambiente do entorno, como solo, obstáculos, dentre outros (PINHO; GALDINO, 2014). Os gráficos comparativos da potencialidade média gerada pelo paraboloide e grupo controle estão dispostos nas Figuras 10 (meses de maio e junho) e 11 (meses de setembro e outubro).

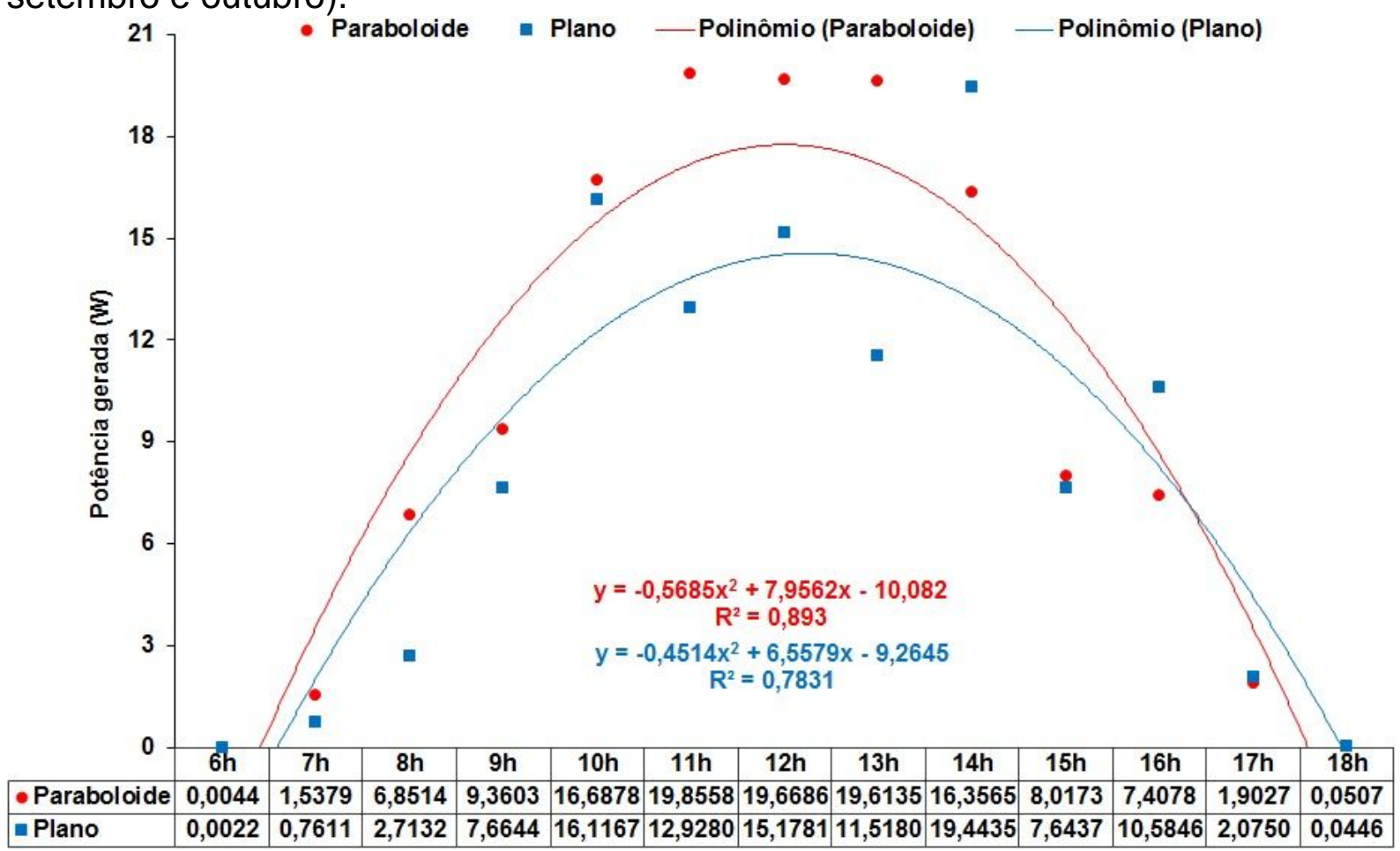

FIGURA 10: Potencialidade gerada pelo paraboloide (vermelho) e grupo controle (azul) nos meses de maio e junho de 2017.

Fonte: Autores.

A curva de tendência do paraboloide foi majoritariamente superior a do grupo controle, isso ocorreu devido ao fato das células terem sido dispostas de forma mais apropriada à luz solar, o que propiciou melhor captação e geração de energia na maior parte do tempo de exposição.

Os pontos médios de potencialidade gerada pelo grupo controle às $14 \mathrm{~h}$ e $16 \mathrm{~h}$ ficaram excepcionalmente acima do paraboloide devido às chuvas recorrentes no período, tendo impossibilitado algumas medições no momento e acarretado em um 
menor peso no cálculo da média de potência gerada pelo grupo controle, resultando em valores superiores aos do paraboloide para ambos horários.

Por meio da integração numérica das funções polinomiais do $2^{\circ}$ grau foi possível mensurar o ganho total de potência do paraboloide (Equação 4) em relação ao grupo controle (Equação 5) nos meses de maio e junho.

$$
\begin{aligned}
& \int_{0}^{12}\left(-0,5685 x^{2}+7,9562 x-10,082\right) d x=124,41 \mathrm{Wdia}^{-1} \\
& \int_{0}^{12}\left(-0,4514 x^{2}+6,5579 x-9,2645\right) d x=100,99 \mathrm{Wdia}^{-1}
\end{aligned}
$$

Comparando-se as Equações 4 e 5, identificou-se que o paraboloide gerou $23,42 \mathrm{~W}$ dia $^{-1}$ a mais que o protótipo plano, ou seja, um desempenho $18,82 \%$ superior ao modelo convencional. Ressalta-se que o coeficiente de correlação de Pearson ( $r$ ) demonstrou alta aderência de ambas curvas experimentais às equações propostas, onde a curva de tendência do paraboloide nesse período apresentou $r=$ 0,95 e a do grupo controle $r=0,89$, ou seja, correlação muito forte e forte, respectivamente, segundo a avaliação qualitativa do grau de correlação entre duas variáveis de Callegari-Jacques (2003).

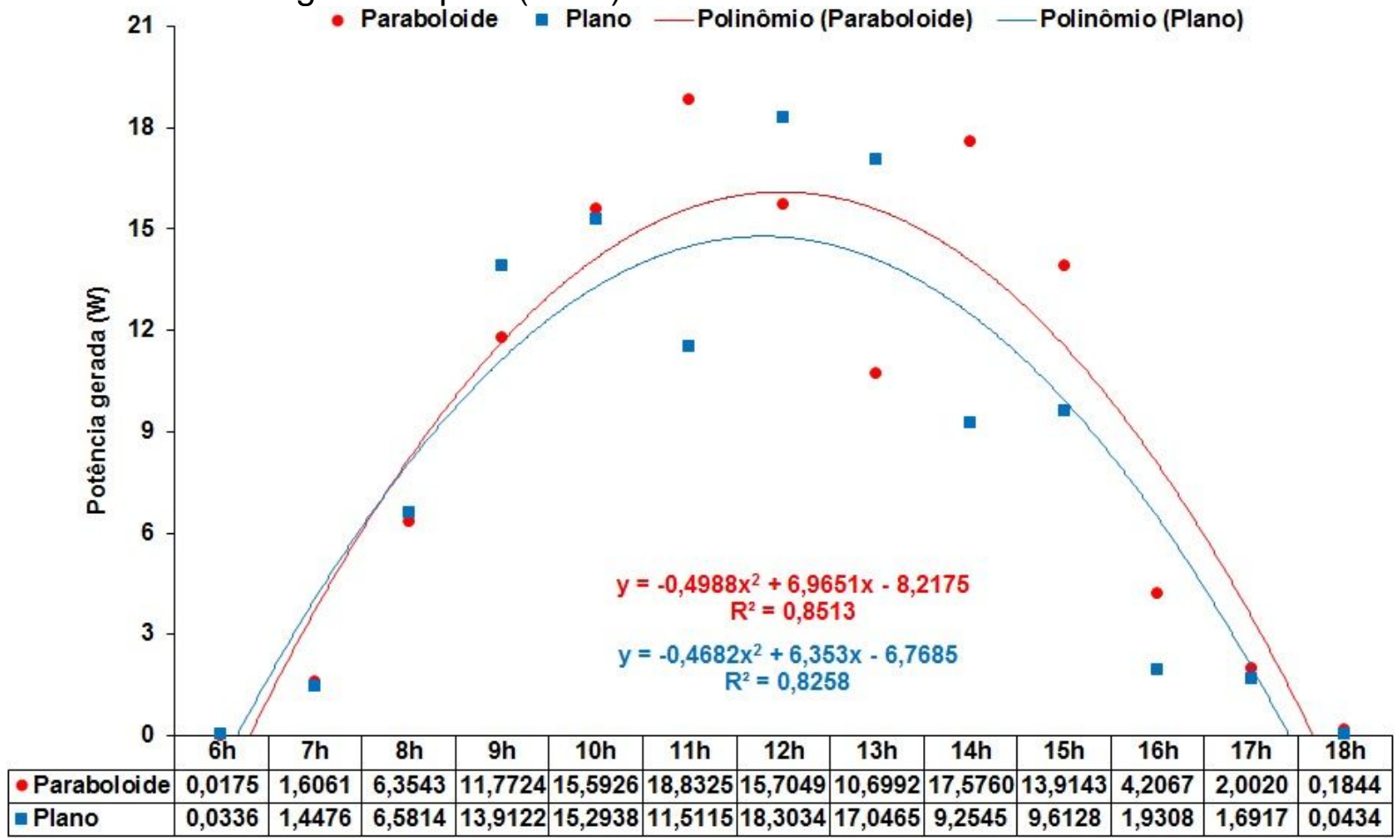

FIGURA 11: Potencialidade gerada pelo paraboloide (vermelho) e grupo controle (azul) nos meses de setembro e outubro de 2017.

Fonte: Autores.

O nascente do Sol nos meses de setembro e outubro, por ter sido próximo do equinócio de setembro, foi ligeiramente inclinado em relação ao ângulo do ponto de medição dos protótipos, beneficiando ambos equitativamente durante as mensurações matutinas, resultando no comportamento de geração de energia semelhante das $6 \mathrm{~h}$ às $9 \mathrm{~h}$. A partir dessa faixa horária percebeu-se o ganho energético superior do paraboloide em relação ao grupo controle. 
Integrando-se ambas funções foi possível avaliar o ganho total de cada módulo nos meses de setembro e outubro, explicitados pelas Equações 6 e 7, respectivamente.

$$
\begin{gathered}
\int_{0}^{12}\left(-0,4988 x^{2}+6,9651 x-8,2175\right) d x=115,57 \mathrm{Wdia}{ }^{-1} \\
\int_{0}^{12}\left(-0,4682 x^{2}+6,353 x-6,7685\right) d x=106,51 \mathrm{Wdia}{ }^{-1}
\end{gathered}
$$

Equiparando-se as Equações 6 e 7, notou-se que neste período o paraboloide gerou $9,06 \mathrm{~W}$ dia $^{-1}$ a mais que o grupo controle, isto é, obteve $7,84 \%$ de geração a mais em relação a este. O curva do paraboloide apresentou $r=0,92$ e a do grupo controle $r=0,91$, ou seja, ambas foram enquadradas como correlação muito forte segundo a classificação de Callegari-Jacques (2003). As constatações evidenciaram a superioridade de desempenho do modelo paraboloide em relação ao modelo convencional mesmo com o elevado índice pluviométrico da área de estudo.

Estimou-se o quantitativo energético possível de ser gerado caso ocorresse a aplicação do modelo proposto neste trabalho para as 2,26 milhões de antenas em desuso no Brasil, levando em consideração apenas o pico de um dia em cada período proposto, disponível na Tabela 1.

TABELA 1: Estimativa do total de energia gerável com a aplicação do módulo proposto nas antenas em desuso no Brasil.

\begin{tabular}{c|c|c} 
Período proposto & $\begin{array}{c}\text { Pico de potência gerada } \\
\text { pelo protótipo em } \\
\text { geometria paraboloide (W) }\end{array}$ & $\begin{array}{c}\text { Total de energia gerada } \\
\text { após aplicação nas 2,26 } \\
\text { milhões de antenas (MW) }\end{array}$ \\
\hline Maio e junho & 19,86 & 45,11 \\
\hline Setembro e outubro & 18,83 & 42,56 \\
\hline
\end{tabular}

Fonte: Autores.

Ressalta-se que a potência limite de uma $\mathrm{PCH}$ é de $30 \mathrm{MW}$, prevista pela Resolução Normativa ํㅜ 673/2015 da ANEEL, art. 2 (ANEEL, 2015). Desse modo, a Tabela 1 evidenciou que apenas no primeiro período haveria a geração de 45,11 MW dia ${ }^{-1}$, equivalente a 1,5 PCH em operação máxima. Já no segundo período seria gerado 42,56 MW dia ${ }^{-1}$, proporcional a 1,42 $\mathrm{PCH}$ em operação máxima. Esses valores exprimem a viabilidade energética do módulo em geometria paraboloide testado neste trabalho.

\section{CONCLUSÃO}

O protótipo proposto nesse artigo apresentou desempenho superior ao modelo convencional, possibilitando a exploração de novos formatos de módulos solares, como tetraédrico, esférico, dentre outros. Além disso, foi possível reutilizar a antena parabólica, material em desuso que vem se acumulando nas residências brasileiras, como demonstrado pelos da ANATEL. Deste modo, uniram-se duas demandas prementes no Brasil: a acessibilização às energias renováveis e o incentivo a reutilização de materiais sem destinação final adequada.

Uma possível aplicação de módulos fotovoltaicos em geometria paraboloide é em postes solares. Esse tipo de poste possui a função de iluminação pública de áreas abertas, mas apresenta perdas energéticas devido ao sistema automatizado 
de rastreamento solar (solar tracking). Com a associação proposta, haveria a vantagem de maior geração de energia, sem custos adicionais com o solar tracking, pois a geometria do módulo viabilizaria a captação em nascente e poente do Sol.

Sugere-se para trabalhos futuros 0 aprofundamento dos estudos comparativos entre os modelos planos convencionais com outras geometrias. Para tal, pode-se partir de experimentos empíricos, como realizado neste estudo, ou testar meios de modelagem matemática, através de softwares computacionais, 0 que enriqueceria ainda mais as discussões dentro da temática de energias renováveis.

\section{REFERÊNCIAS}

AMORIM, I. L. S. Análise de potencial e viabilidade econômica para minigeração solar distribuída no estado do Pará sob o sistema de compensação de energia. Trabalho de Conclusão de Curso. 26p. Universidade do Estado do Pará, Centro de Ciências Naturais e Tecnologia. 2016.

ANATEL - Agência Nacional de Telecomunicações. TV por assinatura assinantes. 2018a. Dados até julho/2018. Disponível em: $<$ http://www.anatel.gov.br/dados/component/content/article?id=215>.

Cloud da ANATEL de dados de TV por Assinatura. 2018b. Dados até julho/2018. <https://cloud.anatel.gov.br/index.php/s/TpaFAwSw7RPfBa8?path=\%2FTV_por_Assi natura>.

Resolução no 488, de 3 de dezembro de 2007 - Seção V (Da Rescisão), Art. 19. Disponível em: <http://www.anatel.gov.br/legislacao/resolucoes/2007/10resolucao-488>.

ANEEL - Agência Nacional de Energia Elétrica. Resolução Normativa no 482, de 17 de abril de 2012. 12p. SGAN 603 módulos I e J - Brasília/DF, 2012.

Resolução Normativa nº 673, de 4 de agosto de 2015. Disponível em: <http://www2.aneel.gov.br/cedoc/atren2015673.pdf>.

BELÉM. Lei no $\mathbf{8 . 6 5 5}$, de 30 de julho de 2008. Dispõe sobre o Plano Diretor do Município de Belém, e dá outras providências. Art. 93. 53p. Belém: Câmara Municipal de Belém, 2008.

BRASIL. Pretendida Contribuição Nacionalmente Determinada para consecução do objetivo da Convenção-Quadro das Nações Unidas Sobre Mudança do Clima. Instrumento entregue em às Nações Unidas em 21 de setembro de 2016. Disponível em: <http://www.itamaraty.gov.br/images/ed_desenvsust/BRASIL-iNDC-portugues.pdf>.

BP - British Petroleum. BP Statistical Review of World Energy June 2016. 65th edition, 48p. BP p.I.c. 1 St James's Square, London SW1Y 4PD, United Kingdom. 2016.

CALLEGARI-JACQUES, S. M. Bioestatística: princípios e aplicações. 255 p. Porto Alegre: Artmed, 2003. 
CAMPOS, M. S.; ALCÂNTARA, L. D. S. Interpretação dos Efeitos de Tempo Nublado e Chuvoso Sobre a Radiação Solar em Belém/PA Para Uso em Sistemas Fotovoltaicos. Revista Brasileira de Meteorologia, v. 31, n. 4 (suppl.), p. 570-579. 2016. Disponível em: <http://dx.doi.org/10.1590/0102-7786312314b20150065>. doi: 10.1590/0102-7786312314b20150065

DIMROTH, F.; TIBBITS, T. N. D; NIEMEYER, M.; PEDRAN, F.; BEUTEL, P. et al. Four-Junction Wafer-Bonded Concentrator Solar Cells. IEEE Journal of Photovoltaics, v. 6, n. 1, January, 2016. Disponível em: <http://dx.doi.org/10.1109/JPHOTOV.2015.2501729>. doi: 10.1109/JPHOTOV.2015.2501729

EPE - Empresa de Pesquisa Energética. Balanço Energético Nacional 2017: Ano base 2016. EPE em parceria com Ministério de Minas e Energia - MME. 296p. Rio de Janeiro, 2017.

FRAUNHOFER ISE. New world record for solar cell efficiency at $46 \%$. $\mathrm{N} 26 / 14$. 1-3 p. Freiburg, December 1st, 2014. Disponível em: < https://www.ise.fraunhofer.de/en/press-media/press-releases/2014/new-world-recordfor-solar-cell-efficiency-at-46-percent.html>.

GOOGLE MAPS. 2017. Coordenadas Geográficas. Disponível em: <https://goo.gl/maps/kAjzcJCPBVT2>. Acesso em 21 de maio de 2017.

IBGE - Instituto Brasileiro de Geografia e Estatística. Estado do Pará - Panorama. Diretoria de Pesquisas, Coordenação de População e Indicadores Sociais, Estimativas da população residente com data de referência 10 de julho de 2018. Disponível em: <https://cidades.ibge.gov.br/brasil/pa/panorama>.

LIMA, J. J. F.; MOYSÉS, A. Como andam Belém e Goiânia. Rio de Janeiro - Letra Capital: Observatório das Metrópoles, 2009.

MOHR, S. H.; EVANS, G. M. Peak Oil: Testing Hubberts Curve via Theoretical Modeling. Natural Resources Research, v. 17, n. 1, p. 5-11p. March 2008. Disponível em <https://doi.org/10.1007/s11053-008-9059-8>. doi: 10.1007/s11053008-9059-8

NREL - National Renewable Energy Laboratory. Best Research-Cell Efficiencies. Revised in july 2018. Disponível em: <https://www.nrel.gov/pv/assets/pdfs/pvefficiencies-07-17-2018.pdf>.

OPEC - Organization of the Petroleum Exporting Countries. Annual Statistical Bulletin (ASB) 2016. 51st edition, 128p. Helferstorferstrasse 17, A-1010 Vienna, Austria. 2016.

PEREIRA, E. B.; MARTINS, F. R.; ABREU, S. L.; RÜTHER, R. Atlas Brasileiro de Energia Solar. 1 ed. 36p. DMA, CPTEC, INPE e MCT. São José dos Campos, 2006.

PINHO, J. T.; GALDINO, M. A. Manual de Engenharia para Sistemas Fotovoltaicos. CEPEL - CRESESB. 47-51p. Edição Revisada e Atualizada, 530p. Rio de Janeiro, 2014. 
PRODANOV, C. C.; FREITAS, E. C. Metodologia do Trabalho Científico [Recurso Eletrônico]: Métodos e Técnicas da Pesquisa e do Trabalho Acadêmico. 2 ed. Novo Hamburgo: Universidade Feevale, 2013.

SERVYCOMS. Instalación y orientación antena de $60 \mathrm{~cm}$ DIRECTVLA. Disponível em: <http://servycoms.blogspot.com.br/2013/05/instalacion-y-orientacionantena-de-60.html>.

W3SAT. Tecnologia DTH: Saiba como funciona. Disponível em $<$ http://w3sat.com.br/tecnologia-dth/>.

WAGNER, E. Por que as antenas são parabólicas? Revista do Professor de Matemática. n. 33, p. 109-113. Sociedade Brasileira de Matemática, 1997. Disponível em: <http://rpm.org.br/cdrpm/33/3.htm>.

WEF - World Economic Forum. Renewable Infrastructure Investment Handbook: A Guide for Institutional Investors. 18p. Committed to Improving the State of the World. 91-93 route de la Capite CH-1223 Cologny/Geneva, Switzerland, 2016.

WWF - World Wide Fund for Nature. Desafios e Oportunidades para a energia solar fotovoltaica no Brasil: recomendações para políticas públicas. $1^{\underline{a}}$ ed. $44 p$. WWF-Brasil - Fundo Mundial para a Natureza. LCA Consultores. Brasília, 2015. 